\title{
Dietary fiber intake from fresh and preserved food and risk of nasopharyngeal carcinoma: observational evidence from a Chinese population
}

Zhi-Ming MAl 1,2, Roger Kai-Cheong NGAN 2,3,4, Dora Lai-Wan KWONG ${ }^{2,3}$, Wai-Tong NG ${ }^{2,3,5}$, Kam-Tong Yuen 2,6, Dennis Kai-Ming I $p^{1,2}$, Yap-Hang CHAN ${ }^{2,7}$, Anne Wing-Mui LEE ${ }^{2,3,8}$, Sai-Yin HO${ }^{1}$, Maria Li LUNG ${ }^{2,3}$ and Tai-Hing $\operatorname{LAM}^{1,2^{*}}$

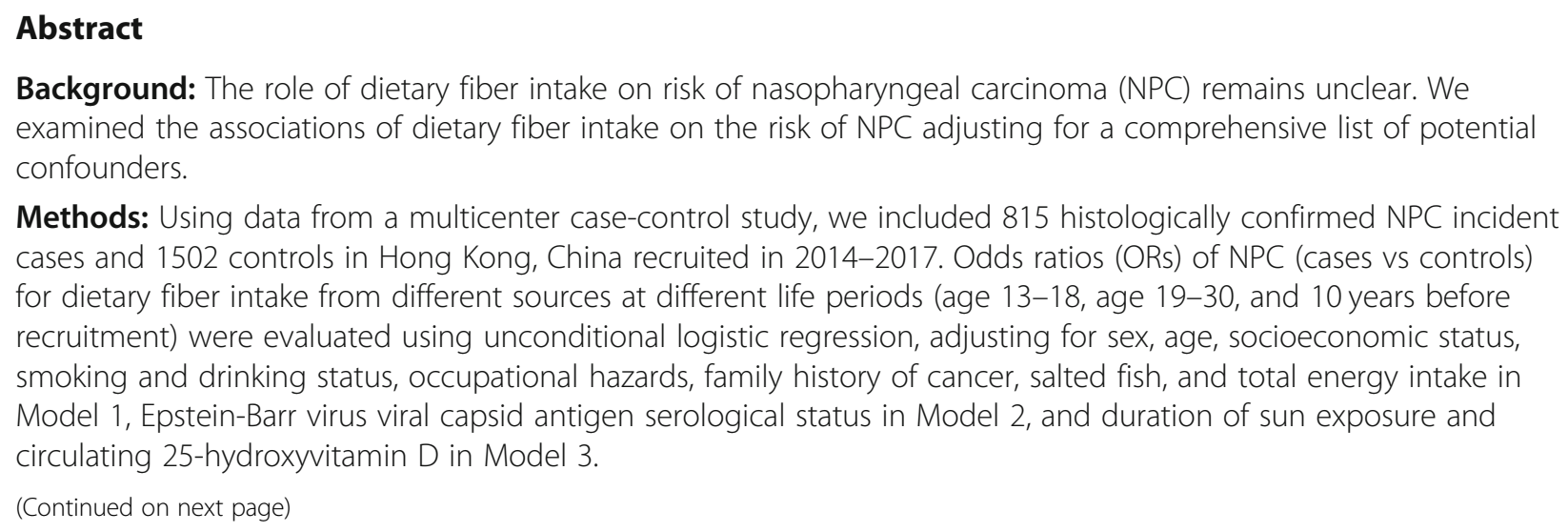

Methods: Using data from a multicenter case-control study, we included 815 histologically confirmed NPC incident cases and 1502 controls in Hong Kong, China recruited in 2014-2017. Odds ratios (ORs) of NPC (cases vs controls) for dietary fiber intake from different sources at different life periods (age 13-18, age 19-30, and 10 years before recruitment) were evaluated using unconditional logistic regression, adjusting for sex, age, socioeconomic status, smoking and drinking status, occupational hazards, family history of cancer, salted fish, and total energy intake in Model 1, Epstein-Barr virus viral capsid antigen serological status in Model 2, and duration of sun exposure and circulating 25-hydroxyvitamin D in Model 3.

\footnotetext{
* Correspondence: hrmrlth@hku.hk

'School of Public Health, Li Ka Shing Faculty of Medicine, The University of Hong Kong, G/F, Patrick Manson Building (North Wing), 7 Sassoon Road, Pok Fu Lam, Hong Kong, SAR, China

${ }^{2}$ Centre for Nasopharyngeal Carcinoma Research (CNPCR), Research Grants Council Area of Excellence Scheme, The University of Hong Kong, Hong Kong, SAR, China

Full list of author information is available at the end of the article
}

(C) The Author(s). 2021 Open Access This article is licensed under a Creative Commons Attribution 4.0 International License, which permits use, sharing, adaptation, distribution and reproduction in any medium or format, as long as you give appropriate credit to the original author(s) and the source, provide a link to the Creative Commons licence, and indicate if changes were made. The images or other third party material in this article are included in the article's Creative Commons licence, unless indicated otherwise in a credit line to the material. If material is not included in the article's Creative Commons licence and your intended use is not permitted by statutory regulation or exceeds the permitted use, you will need to obtain permission directly from the copyright holder. To view a copy of this licence, visit http://creativecommons.org/licenses/by/4.0/ The Creative Commons Public Domain Dedication waiver (http://creativecommons.org/publicdomain/zero/1.0/) applies to the data made available in this article, unless otherwise stated in a credit line to the data. 


\begin{abstract}
(Continued from previous page)
Results: Higher intake of total dietary fiber 10 years before recruitment was significantly associated with decreased NPC risk, with demonstrable dose-response relationship ( $P$-values for trend $=0.001,0.020$ and 0.024 in Models 1-3, respectively). The adjusted ORs $(95 \% \mathrm{Cl})$ in the highest versus the lowest quartile were $0.51(0.38-0.69)$ in Model 1 , $0.48(0.33-0.69)$ in Model 2, and $0.48(0.33-0.70)$ in Model 3. However, the association was less clear after adjustment of other potential confounders (e.g. EBV) in the two younger periods (age of 13-18 and 19-30 years). Risks of NPC were significantly lower for dietary fiber intake from fresh vegetables and fruits and soybean products over all three periods, with dose-response relationships observed in all Models ( $P$-values for trend for age 13-18, age 19-30 and 10 years before recruitment were, respectively, 0.002, 0.009 and 0.001 for Model1; 0.020, 0.031 and 0.003 for Model 2; and 0.022, 0.037 and 0.004 for Model 3). No clear association of NPC risk with dietary fiber intake from preserved vegetables, fruits and condiments was observed.

Conclusion: Our study has shown the protective role of dietary fiber from fresh food items in NPC risk, but no association for total dietary fiber intake was observed, probably because total intake also included intake of preserved food. Further studies with detailed dietary information and in prospective settings are needed to confirm this finding, and to explore the possible underlying biological mechanisms.
\end{abstract}

Keywords: Dietary fiber, Fresh vegetable and fruit, Soybean product, Preserved food, Epstein-Barr virus, Nasopharyngeal carcinoma

\section{Background}

Fiber intake has a broad range of potential health benefits [1], including reduction in the risk of coronary heart disease [2], stroke [3], type 2 diabetes [4], colorectal cancer [5], and head and neck cancer (HNC) [6-8]. Kawakita et al. 2017 [6] conducted a pooled analysis of 10 case-control studies participating in the International Head and Neck Cancer Epidemiology consortium and reported an inverse association of fiber intake with oral and pharyngeal cancer combined, and laryngeal cancer. Their recent prospective study involving 101,700 participants also showed a potential protective role of fiber intake in the development of oral cavity and pharyngeal cancers, but no association for other types of HNC [7]. A prospective longitudinal cohort study of newlydiagnosed head and neck cancer patients showed that pretreatment dietary fiber intake was inversely associated with all-cause mortality [8]. However, these previous studies did not report the association between fiber intake and nasopharyngeal carcinoma (NPC).

$\mathrm{NPC}$, a rare type of $\mathrm{HNC}$ in most parts of the world while relatively common in Southern China, is distinct from other types of HNC in terms of histopathological spectrum, geographical distribution, and etiology [9]. NPC age-standardized incidence rates (ASIRs) in both sexes were less than 1 per 100,000 person-years in most parts of the world [10]. However, over 60,000 new cases per year occurred in China ( $>47 \%$ of all 129,000 NPCs diagnosed globally in 2018) with an ASIR of 3.0 [11]. The ASIR was particular high in south China (28.9 and 11.3 for men and women in Sihui [12], 26.8 and 10.7 in Zhongshan [13], 13.4 and 5.2 in Guangzhou [14], and 11.5 and 2.9 in Hong Kong [15]). Despite identification of several important non-viral environmental risk factors such as consumption of salted fish and preserved vegetable and fruit $[16,17]$, the etiology of NPC related to dietary fiber intake remains debatable. A few epidemiological studies have investigated the role of fiber-rich food intake in NPC [18-25], but only two observational studies (one case-control and one cohort study) reported protective associations of fiber intake with NPC incidence $[26,27]$. However, these two studies were conducted in non-endemic populations with different dietary habits (no consumption of Chinese preserved vegetable and fruit), and they did not adjust for other important risk factors of NPC, especially Epstein-Barr virus (EBV). While EBV infection is a consistently strong risk factor of NPC and is ubiquitously present in the general populations worldwide, it cannot explain the unique geographic disease pattern of NPC [28].

We examined the association between dietary fiber intake across life periods (age 13-18, and 19-30, and 10 years before recruitment) and risk of NPC using data from the Hong Kong Area of Excellence NPC case-control (HKAoENPC) study with adjustment for a comprehensive list of potential confounders. This is a large study to examine the source-specific associations (either from fresh or preserved food items) in an NPC endemic region.

\section{Methods \\ Study population and patient's ascertainment}

The HKAoENPC study is a multicenter case-control study conducted in five major regional hospitals (Queen Mary Hospital, Pamela Youde Nethersole Eastern Hospital, Queen Elizabeth Hospital, Princess Margaret Hospital and Tuen Mun Hospital) that treated up to $75 \%$ of all NPC new cases in Hong Kong, China. Cases and controls were recruited from March 2014 to September 
2017. Detailed descriptions of the study and methods have been previously published $[29,30]$. Briefly, cases were incident NPC patients diagnosed with histological and/or radiological evidence in the Department of Clinical Oncology in the hospitals (response rate 78.4\%) within the past 3 months to minimize the effects of recall bias and lifestyle changes secondary to NPC. Controls were frequency-matched (by 5-year age group and sex; response rate $85.1 \%$ ) new outpatient attendees or new inpatients admitted in specialist clinics of the same hospitals, within the past 12 months and 3 months, respectively. Those controls with a history of NPC, dementia, or suspected symptoms of NPC were excluded. Following the AsiaLymph guideline of the U.S. National Cancer Institute, we also specified that no more than $15 \%$ of controls had one specific type of disease. In addition to self-reported dietary information collected by the Food Frequency Questionnaires (FFQs), the subjects provided $10 \mathrm{ml}$ of peripheral blood on the same date of recruitment. The samples were centrifuged at $3000 \mathrm{rpm}$ at 4 degrees Celsius for $10 \mathrm{~min}$, and then were stored at - 80 degrees Celsius before measurements of EBV VCAIgA serostatus and serum level of 25-hydroxyvitamin D (25OHD).

\section{Dietary fiber intake}

Dietary information on fiber intake was collected with the Semi-Quantitative Food Frequency Questionnaire (which was embedded in the computer-assisted, selfadministered questionnaire) covering 12 high-fiber food items (6 for fresh vegetables, 3 for soybean products, and 3 for preserved foods) over three life periods (age $13-18$, and $19-30$, and 10 years before recruitment). We calculated dietary fiber intake by multiplying the seven categories of frequency (never, < 1 time/month, 1-2 times/month, 1-3 times/week, 4-6 times/week, 1-2 times/day, 3 times/day or more) of consumption and three categories of portion sizes (small $[50 \mathrm{~g}$ ], medium $[75 \mathrm{~g}]$, and large $[100 \mathrm{~g}]$, unless stated otherwise) of each item by its fiber content and summing the products across all food items in a specific period. High-fiber food groups such as fresh vegetables and fruits, soybean products, and preserved foods were assessed according to the Standard Tables of Food Composition in China (2008 No.2). For example, fresh vegetables and fruits included green leafy vegetables (lettuce, Chinese kale, Chinese flowering cabbage, Chinese white cabbage, water spinach, cabbage, broccoli, etc.), vegetables other than green leafy vegetables (cucumber, angled loofah, etc.), carrot, tomatoes, and citrus (orange, mandarin orange, pomelo, tangerine, etc.; portion: 75/150/300 g) and fruits other than citrus. Soybean products included tofu, soybean milk and bean curd. Preserved foods included items such as preserved vegetables (different types of pickled mustard, sour buckwheat head, takuan and pickled white radish), preserved fruits (salty dried plum, dried apricot, licorice olive, sun-dried tangerine peel, dried mango, preserved chayote and raisin), and condiments (shrimp paste, crab paste, soy sauce, fermented black soybean and fermented bean curd; portion: less than half of the spoon, half of the spoon, and a spoon). Participants who did not answer questions related to the frequency or consumption of food items were considered as having "zero intake." Energy-adjustment for nutrients based on about 30 food items in our questionnaire was conducted using the residual method. Our questionnaire of food items had acceptable test-retest reliability (coefficients 0.2-0.9) [29].

\section{Covariate assessment}

Information on covariates collected by the questionnaire included sex, 5-year age group, socioeconomic status (SES) score [range: - 1 (lowest) to 13 (highest), calculated by the subject's, and his/her father's and mother's education, housing type at age 10, personal income, and household income], smoking and drinking status (ever vs never), salted fish consumption (ever vs never), occupational hazards (yes vs no), family history of cancer (yes vs no), and duration of sunlight exposure $(2-<5,5-<8$ and $8+$ vs $<2 \mathrm{~h} /$ day).

Antibody of IgA against EBV viral capsid antigen (VCA-IgA) was measured using a commercial kit (EUROIMMUN AG, Lübeck, Germany) based on the standard ELISA method. Results were analyzed semiquantitatively by calculating the ratio of the optical density (OD) value of the sample over the optical OD of the calibrator, expressed as relative OD. According to the manufacturer's instruction, the serostatus of VCA-IgA was classified as seronegative (rOD value: $<1.2$ ) or seropositive (rOD value: $\geq 1.2$ ). Serum level of $25 \mathrm{OHD}$ was measured using validated enzyme immunoassay (Abbott ARCHITECT i2000SR). The sensitivity was $4.75 \mathrm{nmol} / \mathrm{L}$ and the range was $0-400 \mathrm{nmol} / \mathrm{L}$, and no sample had a concentration below or above these limits. The intraassay coefficient of variation was $4.3-8.1 \%$ by repeating measurements of 50 samples, and the reliability coefficient was acceptable $(<10 \%)$. Circulating $25 \mathrm{OHD}$ was classified into three a priori categorizes based on clinically relevant cut-off points for the main analysis: $<37.5$ (deficient), $37.5<75$ (insufficient), and $\geq 75$ (sufficient) $\mathrm{nmol} / \mathrm{L}$ [31].

\section{Statistical analysis}

To assess the difference between NPC cases and controls, $t$-test and $\chi^{2}$ test were used to compare the mean of continuous factors, and proportions of categorical factors, respectively. To examine the associations of NPC with quartiles of total dietary fiber intake, dietary fiber 
intake from different sources (from fresh vegetables and fruits, and soybean products, or from preserved vegetables, fruits and condiments) at each life period (age 1318 , and 19-30, and 10 years before recruitment), odds ratio (OR) and 95\% confidence interval (CI) were calculated using unconditional logistic regression. The lowest quartile was set as the reference. Model 1 was adjusted for sex, 5-year age group, SES score, smoking and drinking status, occupational hazards, family history of cancer, salted fish and total energy intake as appropriate. Additional variables were adjusted for in Model 2 (EBV VCA-IgA serological status) and Model 3 (EBV VCAIgA serological status, duration of sun exposure and circulating 25OHD). Missing values were classified as separate categories and included as indicator variables in the models. A sensitivity analysis was conducted on only World Health Organization III subtype NPC (the predominant subtype, about $90 \%$ in NPC endemic areas) [32], which did not substantially affect our results. To assess dose-response effect between exposure and NPC risk, linear trend was tested for each continuous exposure with $P$ values for trend $<0.05$ indicating significance. Interactions by potential risk factors of NPC were tested based on the likelihood ratio test by introducing interaction terms into the Model 3. We repeated the analyses stratified by factors with any $P$-values for interaction $<0.2$.

All statistical tests were two-sided with a specific typeI error of 0.05, and analyses were performed in Stata/SE version 15.0 software (STATA corporation, College Station, Texas, USA).

\section{Results}

Compared with 1502 controls, the 815 NPC cases were older, had a greater proportion of men, and those with lower SES, family history of NPC, ever-smoking, EBV seropositivity, and exposure to any occupational hazards $(P$-values $<0.001)$. NPC cases also consumed less green leaf vegetables, other vegetables, carrot, tomato, citrus, fruits other than citrus and tofu, but more condiments than controls $(P$-values $<0.05)$. No difference for other factors was observed $(P>0.15)$ (Table 1$)$.

Higher intake of total dietary fiber 10 years before recruitment was significantly associated with decreased NPC risk, with demonstrable dose-response relationship $(P$-values for trend $=0.001,0.020$ and 0.024 in Models $1-3$, respectively). The adjusted ORs $(95 \% \mathrm{CI})$ in the highest versus the lowest quartile were $0.51(0.38-0.69)$ in Model 1, 0.48 (0.33-0.69) in Model 2, and 0.48 (0.330.70 ) in Model 3. While higher intake of total dietary fiber both at age of 13-18 and 19-30 years was also significantly associated with decreased NPC risk with doseresponse relationships in Model 1 (OR in the highest versus the lowest quartile $=0.56,95 \% \mathrm{CI}=0.40-0.79, P$ for trend $=0.006$, and $0.49, \quad 0.37-0.66, \quad 0.003$, respectively), these dose-response relationships became non-significant after additionally adjusting for EBV VCA-IgA in Model 2, and sun exposure and 25OHD in Model 3. Risks of NPC were also significantly lower for dietary fiber intake from fresh vegetables and fruits and soybean products over all three periods, with doseresponse relationships $(P$-values for trend $=0.002$ for age of $13-18$ years, 0.009 for age of $19-30$ years and 0.001 for 10 years before recruitment, $0.020,0.031$ and 0.003 , and $0.022,0.037$ and 0.004 in Models $1-3$, respectively) observed in all Models. No clear association of NPC risk with dietary fiber intake from preserved vegetables, fruits and condiments was observed (Table 2).

No evidence $(P$-values for interaction $>0.20)$ of interaction was found by sex, age, drinking status, occupational hazards, family history of cancer, consumption of salted fish, duration of sun exposure and circulating levels of 25-hydroxyvitamin D for the association between dietary fiber intake and NPC, except for SES and tobacco use. Higher NPC risks were observed for the highest quartile of dietary fiber intake from preserved vegetables, fruits and condiments 10 years before recruitment in participants with high SES (adjusted OR $=2.30$, 95\% CI $=1.26-4.19)$, but not with low SES (0.92-0.581.45) $(P$ for interaction $=0.067)$. In addition, risks of NPC were significantly lower for higher total dietary fiber intake or intake from fresh vegetables and fruits and soybean products 10 years before recruitment only in never smokers, but not in ever smokers. The $P$-values for trend were 0.025 and 0.009 in never smokers, and 0.27 and 0.41 in ever smokers $(P$-values for interaction $=$ 0.112 and 0.189 , respectively) (Table 3 ).

\section{Discussion}

Our study has shown an inverse association between total dietary fiber intake 10 years before recruitment and NPC risk in Hong Kong, where NPC is endemic. The association was less clear after adjustment of other potential confounders (e.g. EBV) in the two younger periods (age of 13-18 and 19-30 years). Our results can strengthen the evidence for dietary fiber intake from fresh foods as a protective factor of NPC, which were consistent across life periods, but we found no evidence for an association for dietary fiber intake from preserved foods. We also observed a multiplicative interaction (marginal $P$-values $<0.20$ ) with SES and smoking for the association between fiber intake and NPC risk. The combination of high SES \& high dietary fiber intake from preserved foods was associated with a higher excess risk of NPC, whereas the protective role of dietary fiber intake (total or from fresh foods) was only observed in never smokers.

These findings are consistent with results from one case-control study and one prospective cohort study 
Table 1 Distribution of 815 cases of NPC and 1502 controls by demographics, putative risk factors of NPC, and factors related to dietary fiber intake in Hong Kong, China, 2014-2017

\begin{tabular}{|c|c|c|c|c|c|}
\hline \multirow[t]{2}{*}{ Variable } & \multicolumn{2}{|c|}{ NPC cases $(N=815)$} & \multicolumn{2}{|c|}{ Controls $(N=1502)$} & \multirow[t]{2}{*}{$P$-value $\neq$} \\
\hline & $\mathrm{n}$ & $\%$ & $\mathrm{n}$ & $\%$ & \\
\hline Mean socioeconomic status score $(\mathrm{SD}) \neq$ & 3 & 2.8 & 3.7 & 3.0 & $<0.001$ \\
\hline Family history of cancer & & & & & $<0.001$ \\
\hline None & 288 & 35.3 & 753 & 50.1 & \\
\hline Yes, but not NPC & 269 & 33.0 & 561 & 37.4 & \\
\hline Yes, NPC & 134 & 16.4 & 77 & 5.1 & \\
\hline Don't know & 124 & 15.2 & 111 & 7.4 & \\
\hline Exposure to any occupational hazards & & & & & $<0.001$ \\
\hline Never & 285 & 35.0 & 758 & 50.5 & \\
\hline Ever & 399 & 49.0 & 597 & 39.8 & \\
\hline Don't know & 131 & 16.1 & 147 & 9.8 & \\
\hline Smoking & & & & & $<0.001$ \\
\hline Never & 417 & 51.2 & 945 & 62.9 & \\
\hline Ever & 392 & 48.1 & 552 & 36.8 & \\
\hline Refuse to answer & 6 & 0.7 & 5 & 0.3 & \\
\hline Alcohol drinking & & & & & 0.19 \\
\hline Never & 512 & 62.8 & 977 & 65.1 & \\
\hline$\leq 210 \mathrm{~g} /$ week & 203 & 24.9 & 377 & 25.1 & \\
\hline$>210 \mathrm{~g} /$ week & 100 & 12.3 & 148 & 9.9 & \\
\hline EBV VCA-lgAt & & & & & $<0.001$ \\
\hline Seronegative & 56 & 10.8 & 902 & 88.1 & \\
\hline Seropositive & 463 & 89.2 & 122 & 11.9 & \\
\hline \multicolumn{6}{|l|}{ Sources of dietary fiber intake, g/week } \\
\hline \multicolumn{6}{|l|}{ Fresh } \\
\hline Green leafy vegetables & & & & & 0.001 \\
\hline$<9.2$ & 327 & 40.1 & 502 & 33.4 & \\
\hline $9.2-<17.2$ & 384 & 47.1 & 731 & 48.7 & \\
\hline $17.2-<52$ & 93 & 11.4 & 250 & 16.6 & \\
\hline Don't know/missing & 11 & 1.4 & 19 & 1.3 & \\
\hline Other vegetables & & & & & 0.013 \\
\hline$<2.2$ & 475 & 58.3 & 831 & 55.3 & \\
\hline $2.2-<5.5$ & 175 & 21.5 & 340 & 22.6 & \\
\hline $5.5-<24$ & 119 & 14.6 & 377 & 18.4 & \\
\hline Don't know/missing & 46 & 5.6 & 54 & 3.6 & \\
\hline Carrot & & & & & $<0.001$ \\
\hline$<0.6$ & 318 & 39.0 & 521 & 34.7 & \\
\hline $0.6-<2.4$ & 199 & 24.4 & 402 & 26.8 & \\
\hline $2.4-<34$ & 132 & 16.2 & 361 & 24.0 & \\
\hline Don't know/missing & 166 & 20.4 & 218 & 14.5 & \\
\hline Tomato & & & & & $<0.001$ \\
\hline$<1.9$ & 366 & 44.9 & 618 & 41.2 & \\
\hline $1.9-<4.7$ & 331 & 40.6 & 629 & 41.9 & \\
\hline $4.7-<40$ & 43 & 5.3 & 156 & 10.4 & \\
\hline Don't know/missing & 75 & 9.2 & 99 & 6.6 & \\
\hline Citrus & & & & & 0.006 \\
\hline
\end{tabular}


Table 1 Distribution of 815 cases of NPC and 1502 controls by demographics, putative risk factors of NPC, and factors related to dietary fiber intake in Hong Kong, China, 2014-2017 (Continued)

\begin{tabular}{|c|c|c|c|c|c|}
\hline \multirow[t]{2}{*}{ Variable } & \multicolumn{2}{|c|}{ NPC cases $(N=815)$} & \multicolumn{2}{|c|}{ Controls $(N=1502)$} & \multirow[t]{2}{*}{$P$-value } \\
\hline & $\mathrm{n}$ & $\%$ & $n$ & $\%$ & \\
\hline$<0.6$ & 218 & 26.8 & 344 & 22.9 & \\
\hline $0.6-<6.7$ & 339 & 41.6 & 583 & 38.8 & \\
\hline $6.7-<29$ & 73 & 9.0 & 189 & 12.6 & \\
\hline Don't know/missing & 185 & 22.7 & 386 & 25.7 & \\
\hline Fruits other than citrus & & & & & $<0.001$ \\
\hline$<2.2$ & 379 & 46.5 & 574 & 38.2 & \\
\hline $2.2-<3.0$ & 216 & 26.5 & 439 & 29.2 & \\
\hline $3.0-<32$ & 159 & 19.5 & 394 & 26.2 & \\
\hline Don't know/missing & 61 & 7.5 & 95 & 6.3 & \\
\hline
\end{tabular}

Soybean products

\section{Tofu}

$$
\begin{aligned}
& <1.2 \\
& 1.2-<4.0 \\
& 4.0-<51
\end{aligned}
$$

Don't know/missing

\section{Soymilk}

$$
\begin{aligned}
& <0.2 \\
& 0.2-<0.4 \\
& 0.4-<11 \\
& \text { Don't know/missing }
\end{aligned}
$$

Bean curd, servings/week

$$
<0.1
$$$$
0.1-<0.2
$$$$
0.2-<10
$$

Don't know/missing

Preserved vegetables, servings/week

$$
<0.5
$$$$
0.5-<2.7
$$$$
2.7-<44
$$

Don't know/missing

Preserved fruits, servings/week

$$
<0.3
$$$$
0.3-<0.7
$$$$
0.7-<33
$$

Don't know/missing

Condiments, servings/week

$\begin{array}{lll}<0.5 & 260 & 31.9 \\ 0.5-<2.2 & 283 & 34.7 \\ 2.2-<24 & 211 & 25.9 \\ \text { Don't know/missing } & 61 & 7.5\end{array}$

Abbreviation: NPC Nasopharyngeal carcinoma; SD Standard deviation; $g$ Gram; EBV VCA-lgA, IgA against Epstein-Barr virus viral capsid antigen VCA ₹ t-test and Chi-square test were used to compare the mean of continuous factors, and proportions of categorical factors between cases and controls, respectively

₹ Socioeconomic status score ranged from -1 (lowest socioeconomic status) to 13 (highest socioeconomic status), and was calculated by the subject's, and his/her father's and mother's education, personal income, household income and housing type at age 10

† Epstein-Barr virus viral capsid antibody (EBV VCA-IgA) levels: optical density value $<1.2$ (seronegative) or $\geq 1.2$ (seropositive)
0.015
5.7

13.1

19.0

3.6

8

$\begin{array}{ll}552 & 30.4\end{array}$

$408 \quad 27.2$

$86 \quad 5$

\section{e‡}

(1)




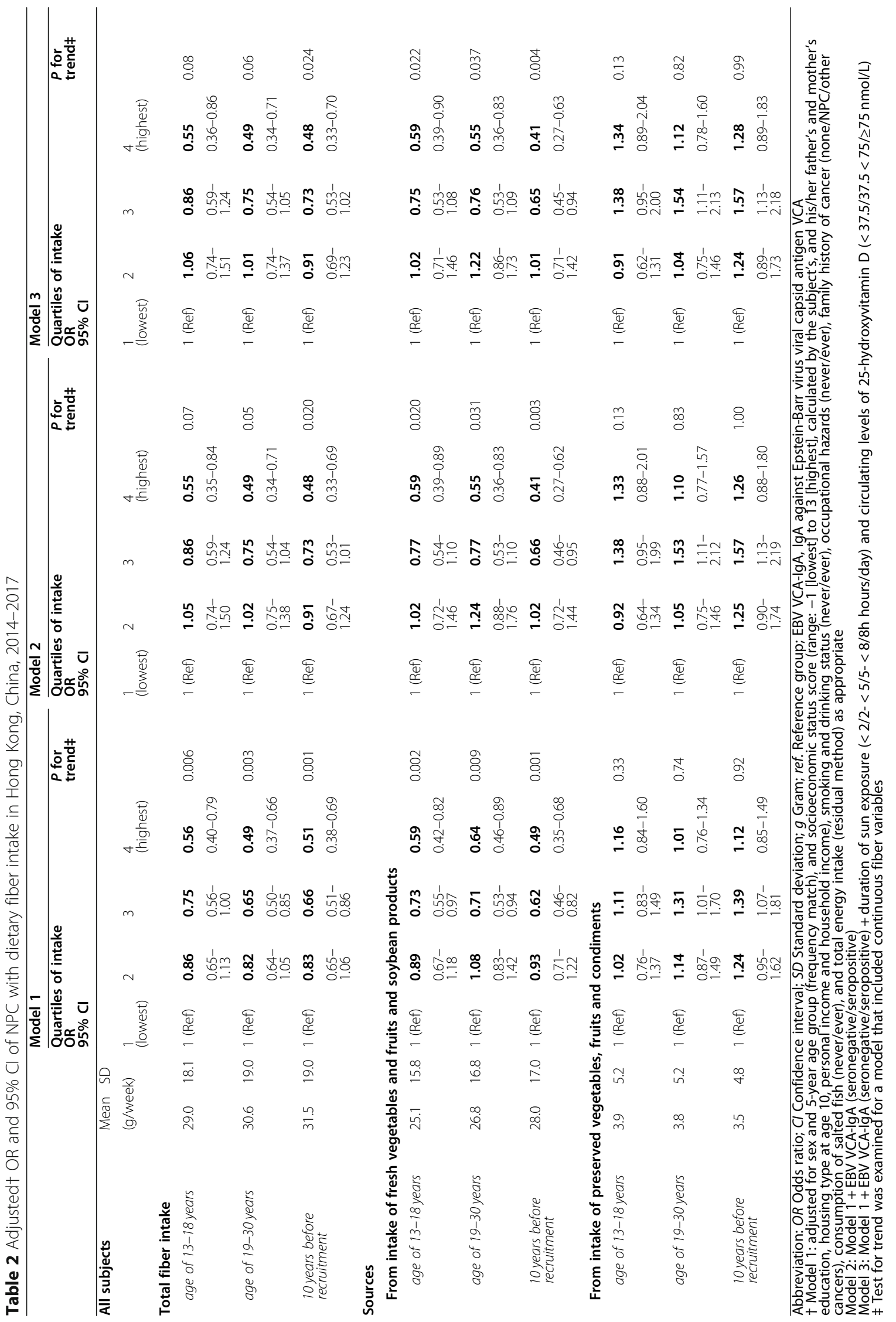


Table 3 Adjusted + OR and 95\% Cl of NPC with dietary fiber intake by socioeconomic status and tobacco use in Hong Kong China, 2014-2017

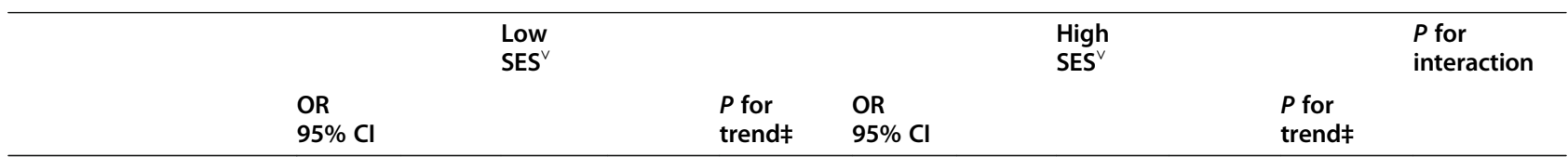

\section{All subjects}

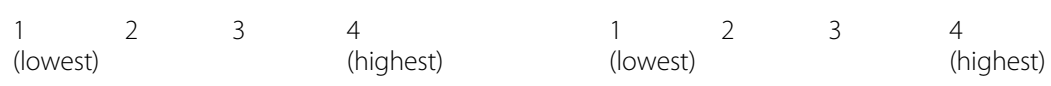

Total fiber intake

10 years before

recruitment

\begin{tabular}{|c|c|c|c|}
\hline \multirow[t]{2}{*}{1 (Ref) } & 0.88 & 0.78 & 0.46 \\
\hline & $\begin{array}{l}0.59- \\
1.30\end{array}$ & $\begin{array}{l}0.51- \\
1.20\end{array}$ & $\begin{array}{l}0.28- \\
0.74\end{array}$ \\
\hline
\end{tabular}

$\begin{array}{lllll}1 \text { (Ref) } & \mathbf{0 . 9 3} & \mathbf{0 . 6 7} & \mathbf{0 . 5 1} & 0.07 \\ & 0.56- & 0.40- & 0.28- & \\ 1.55 & 1.11 & 0.94\end{array}$

\section{Sources}

From intake of fresh vegetables and fruits and soybean products

$\begin{array}{llllllllll}\begin{array}{l}10 \text { years before } \\ \text { recruitment }\end{array} & 1 \text { (Ref) } & \mathbf{0 . 9 2} & \mathbf{0 . 7 3} & \mathbf{0 . 5 2} & 0.27 & 1 \text { (Ref) } & \mathbf{0 . 9 2} & \mathbf{0 . 6 6} & \mathbf{0 . 3 5} \\ & & 0.62- & 0.48- & 0.33- & & & 0.56- & 0.39- & 0.19- \\ & & 1.35 & 1.11 & 0.85 & & & 1.52 & 1.12 & 0.64\end{array}$

From intake of preserved vegetables, fruits and condiments

\begin{tabular}{|c|c|c|c|c|}
\hline \multirow{2}{*}{$\begin{array}{l}10 \text { years before } \\
\text { recruitment }\end{array}$} & 1 (Ref) & 1.19 & 1.29 & 0.92 \\
\hline & & $\begin{array}{l}0.78- \\
1.83\end{array}$ & $\begin{array}{l}0.84- \\
1.97\end{array}$ & $\begin{array}{l}0.58- \\
1.45\end{array}$ \\
\hline
\end{tabular}

Never smokers

$\mathrm{OR}$

$95 \% \mathrm{Cl}$

All subjects

$$
\begin{array}{llll}
1 & 2 & 3 & 4 \\
\text { (lowest) } & & & \text { (highest) }
\end{array}
$$

$\begin{array}{ll}P \text { for } & \text { OR } \\ \text { trend } \neq & 95 \% \mathrm{Cl}\end{array}$

$\begin{array}{llll}1 \text { (Ref) } & \mathbf{1 . 5 1} & \mathbf{2 . 2 1} & \mathbf{2 . 3 0} \\ & 0.87- & 1.27- & 1.26- \\ 2.62 & 3.85 & 4.19\end{array}$

0.11

Ever smokers

Total fiber intake

10 years before

recruitment

$\begin{array}{lllll}1 \text { (Ref) } & \mathbf{0 . 7 3} & \mathbf{0 . 5 3} & \mathbf{0 . 4 2} & 0.025 \\ & 0.47- & 0.34- & 0.26- & \\ & 1.13 & 0.82 & 0.70 & \end{array}$

$P$ for

trend $\neq$

\section{Sources}

From intake of fresh vegetable and fruit and soybean product

\begin{tabular}{|c|c|c|c|c|c|c|c|c|c|c|}
\hline \multirow{2}{*}{$\begin{array}{l}10 \text { years before } \\
\text { recruitment }\end{array}$} & \multirow[t]{2}{*}{1 (Ref) } & 0.78 & 0.50 & 0.35 & \multirow[t]{2}{*}{0.009} & \multirow[t]{2}{*}{1 (Ref) } & 1.09 & 1.02 & 0.51 & \multirow[t]{2}{*}{0.41} \\
\hline & & $\begin{array}{l}0.51- \\
1.19\end{array}$ & $\begin{array}{l}0.32- \\
0.77\end{array}$ & $\begin{array}{l}0.22- \\
0.58\end{array}$ & & & $\begin{array}{l}0.70- \\
1.69\end{array}$ & $\begin{array}{l}0.62- \\
1.68\end{array}$ & $\begin{array}{l}0.28- \\
0.92\end{array}$ & \\
\hline \multicolumn{11}{|c|}{ rom intake of preserved vegetable, fruit and condiment } \\
\hline \multirow{2}{*}{$\begin{array}{l}10 \text { years before } \\
\text { recruitment }\end{array}$} & \multirow[t]{2}{*}{1 (Ref) } & 1.32 & 1.69 & 1.72 & \multirow[t]{2}{*}{0.36} & \multirow[t]{2}{*}{1 (Ref) } & 1.18 & 1.47 & 0.95 & \multirow[t]{2}{*}{0.28} \\
\hline & & $\begin{array}{l}0.84- \\
2.07\end{array}$ & $\begin{array}{l}1.08- \\
2.64\end{array}$ & $\begin{array}{l}1.05- \\
2.80\end{array}$ & & & $\begin{array}{l}0.71- \\
1.98\end{array}$ & $\begin{array}{l}0.88- \\
2.47\end{array}$ & $\begin{array}{l}0.55- \\
1.62\end{array}$ & \\
\hline
\end{tabular}

Abbreviation: OR Odds ratio; CI Confidence interval; SES Socioeconomic status score; $g$ Gram; ref. Reference group; EBV VCA-IgA, IgA against Epstein-Barr virus viral capsid antigen VCA

† Adjusted for sex and 5-year age group (frequency match), and SES score (range: -1 [lowest] to 13 [highest], calculated by the subject's, and his/her father's and mother's education, housing type at age 10, personal income and household income), smoking and drinking status (never/ever), occupational hazards (never/ ever), family history of cancer (none/NPC/other cancers), consumption of salted fish (never/ever), and total energy intake (residual method), EBV VCA-IgA (seronegative/seropositive), duration of sun exposure $(<2 / 2-<5 / 5-<8 / 8 \mathrm{~h}$ hours/day) and circulating levels of 25 -hydroxyvitamin $\mathrm{D}(<37.5 / 37.5<75 / \geq 75 \mathrm{nmol} / \mathrm{L})$ $\checkmark$ Low SES: SES score < 4; High SES: SES score $\geq 4$

₹ Test for trend was examined for a model that included continuous fiber variables

$P$-values for interactions by sex, age $(<40,40-<65,65+)$, drinking status (never, ever), occupational hazards (never/ever), family history of cancer (none/NPC/other cancers), consumption of salted fish (never/ever), duration of sun exposure $(<5 / 5 \mathrm{~h}$ hours/day) and circulating levels of 25 -hydroxyvitamin $D(<37.5 / 37.5<75 / \geq 75$ $\mathrm{nmol} / \mathrm{L})$ for the association between dietary fiber intake and NPC ranged from $0.22-0.99$, except for SES and tobacco use $(P$ for interaction $<0.20)$ 
both in NPC non-endemic regions [26, 27]. An Italian case-control study by Bidoli et al. on 198 NPC cases and 594 non-NPC controls during 1992 to 2008 using total fiber intake based on a 78-item food frequency questionnaire found a suggestive inverse association between total fiber intake and NPC risk (OR $=0.58$ in the highest versus the lowest quartile of intake, 95\% CI $=0.34-0.96$ ) [26]. A prospective analysis by Kasum et al. on 18 NPC cases in 34,351 postmenopausal women in the Iowa Women's Health Cohort Study in the United States found a nonsignificant inverse association between total fiber intake and NPC risk [27]. Both studies did not account for potential confounders (e.g. EBV) and fiber intake from preserved foods, and did not examine potential interactions by other putative risk factors. Epidemiological studies from NPC endemic regions have shown inverse associations of NPC risk with consumption of fresh vegetables and fruits [18-25], and our findings are somewhat in agreement with these results. However, these studies did not calculate total dietary fiber intake.

While further prospective studies in other populations are needed to confirm this finding, several biological mechanisms have been proposed to explain the protective role of fiber intake in NPC. One possibility is that fiber is known to have anti-inflammatory effects [33, 34]. Another possibility is that a high fiber intake may simply be an indicator of a healthier lifestyle (e.g. never smoked) [35]. Indeed, our results from stratified analysis by tobacco use support this hypothesis, as total dietary fiber intake and intake from fresh foods were significantly associated with lower risk of NPC in never smokers only.

A strength of our study was that it has included a comprehensive list of potential confounders, and is the first to show the role of dietary fiber intake from fresh and preserved food items in an NPC endemic region. The limitations of our study are common to those that use FFQs to estimate dietary intakes [36]. The estimation of intake of dietary fiber using FFQs may have considerable error. In addition, as a hospital-based casecontrol study, Berkson's bias, recall bias and residual confounding could be present. Because we used incident cases in our case-control study, indirect Berkson's bias (exposure-disease associations that arise because another disease is associated with the exposure under study) is unlikely [37]. The intake of dietary fiber in our control group was lower than that in the general Hong Kong population [38], suggesting that our results might have underestimated the protective role of fiber intake in NPC. However, recruiting healthy controls from the community would not be the best method due to recall bias from healthy subjects (versus NPC and other hospital patients). Our hospital patients had more similar mindset and recall behavior with NPC patients than community controls, resulting in less subjective bias. We conducted a test-retest reliability study to assess recall error, and found that the questionnaire data of most NPC etiology factors of our NPC cases and controls had acceptable reliability [29]. While we had adjusted for the most relevant and potential confounders, residual confounding cannot be ruled out. The association between dietary fiber and NPC risk could have been underestimated because the dietary variables such as rice and wheat were imperfectly measured in our questionnaire.

\section{Conclusion}

Our study has shown the protective role of dietary fiber from fresh food items in NPC risk, but no association for total dietary fiber intake was observed, probably because total intake also included intake of preserved food. Our results suggest that increased fiber intake from fresh vegetables, fruits, and soybean products but not preserved vegetables, fruits, and condiments could be an option for achieving an adequate fiber intake for the prevention of NPC. Further studies with detailed dietary information and in prospective settings are needed to confirm this finding, and to explore the possible underlying biological mechanisms.

\section{Acknowledgments \\ The chief acknowledgment is to the subjects who provided information for this study, and the research staff and Dr. Jia-Huang Lin and Alice Wan-Ying NG for data collection.}

\section{Authors' contributions}

ZMM and THL designed the study; ZMM performed the statistical analysis, and drafted the manuscript; ZMM, RKCN, DLWK, WTN, AWML, MLL collected data. All authors revised it critically for important intellectual content and contributed to final approval of the paper.

\section{Funding}

This study was supported by the Hong Kong RGC Area of Excellence Scheme (Grant Number AoE/M-06/08), and the World Cancer Research Fund UK (WCRF UK) and Wereld Kanker Onderzoek Fonds (WCRF NL), as part of the WCRF International Grant Programme (Grant 2011/460). The sponsors of the study had no role in study design, data collection, data analysis, data interpretation, or report writing.

\section{Availability of data and materials \\ The datasets used and/or analyzed during the current study are available from the corresponding author on reasonable request.}

\section{Ethics approval and consent to participate}

Informed consent was obtained from all individual subjects included in the study.

The Institutional Review Board of the HKU/Hospital Authority HK West Cluster (UW 11-192), the HK East Cluster Research Ethics Committee (HKEC2012-043), the Research Ethics Committee of the Hospital Authority Kowloon Central/Kowloon East (KC/KE-13-0115/ER-2), the Research Ethics Committee of the Kowloon West Cluster [KW/EX-13-073(63-11)], and the NTW Cluster Clinical \& Research Ethics Committee (NTWC/CREC/1239-13) approved the study.

Consent for publication

Not applicable. 


\section{Competing interests}

The authors declare no conflict of actual or potential competing financial interests.

\section{Author details \\ 'School of Public Health, Li Ka Shing Faculty of Medicine, The University of Hong Kong, G/F, Patrick Manson Building (North Wing), 7 Sassoon Road, Pok Fu Lam, Hong Kong, SAR, China. ${ }^{2}$ Centre for Nasopharyngeal Carcinoma Research (CNPCR), Research Grants Council Area of Excellence Scheme, The University of Hong Kong, Hong Kong, SAR, China. ${ }^{3}$ Department of Clinical Oncology, Li Ka Shing Faculty of Medicine, The University of Hong Kong, Hong Kong, SAR, China. ${ }^{4}$ Department of Clinical Oncology, Queen Elizabeth Hospital, Hong Kong, SAR, China. ${ }^{5}$ Department of Clinical Oncology, Pamela Youde Nethersole Eastern Hospital, Hong Kong, SAR, China. ${ }^{6}$ Department of Oncology, Princess Margaret Hospital, Hong Kong, SAR, China. ${ }^{7}$ Department of Medicine, Queen Mary Hospital, The University of Hong Kong, Hong Kong, SAR, China. ${ }^{8}$ Clinical Oncology Center, The University of Hong Kong-Shenzhen Hospital, Shenzhen, China.}

\section{Received: 2 November 2020 Accepted: 18 January 2021} Published online: 02 February 2021

\section{References}

1. Reynolds A, Mann J, Cummings J, Winter N, Mete E, Te Morenga L. Carbohydrate quality and human health: a series of systematic reviews and meta-analyses. Lancet. 2019;393:434-45.

2. Hartley L, May MD, Loveman E, Colquitt JL, Rees K. Dietary fibre for the primary prevention of cardiovascular disease. Cochrane Database Syst Rev. 2016;(1):CD011472. https://doi.org/10.1002/14651858.CD011472.pub2.

3. Threapleton DE, Greenwood DC, Evans CE, Cleghorn CL, Nykjaer C, Woodhead C, Cade JE, Gale CP, Burley VJ. Dietary fiber intake and risk of first stroke: a systematic review and meta-analysis. Stroke. 2013;44:1360-8.

4. Silva FM, Kramer CK, de Almeida JC, Steemburgo T, Gross JL, Azevedo MJ. Fiber intake and glycemic control in patients with type 2 diabetes mellitus: a systematic review with meta-analysis of randomized controlled trials. Nutr Rev. 2013;71:790-801.

5. World Cancer Research Fund/American Institute for Cancer Research. Continuous Update Project Expert Report 2018. Diet, nutrition, physical activity and colorectal cancer. Available at dietandcancerreport.org.

6. Kawakita D, Lee YCA, Turati F, Parpinel M, Decarli A, Serraino D, Matsuo K, Olshan AF, Zevallos JP, Winn DM. Dietary fiber intake and head and neck cancer risk: a pooled analysis in the international head and neck Cancer epidemiology consortium. Int J Cancer. 2017;141:1811-21.

7. Kawakita D, Lee YCA, Gren LH, Buys SS, La Vecchia C, Hashibe M. Fiber intake and the risk of head and neck cancer in the prostate, lung, colorectal and ovarian (PLCO) cohort. Int J Cancer. 2019;145:2342-8.

8. Maino Vieytes CA, Mondul AM, Li Z, Zarins KR, Wolf GT, Rozek LS, Arthur AE. Dietary Fiber, whole grains, and head and neck Cancer prognosis: findings from a prospective cohort study. Nutrients. 2019;11:2304.

9. Lee AW, Lung ML, Ng WT. Nasopharyngeal carcinoma: from etiology to clinical practice. Lodon: Academic Press; 2019.

10. Chen YP, Chan AT, Le QT, Blanchard P, Sun Y, Ma J. Nasopharyngeal carcinoma. Lancet. 2019;394:64-80.

11. Ferlay J, Soerjomataram I, Ervik M, et al. GLOBOCAN 2012 v1.0, Cancer incidence and mortality worldwide: IARC CancerBase no. 11. Lyon, France: International Agency for Research on Cancer; 2013. Available from: http:// globocan.iarc.fr, Accessed 24 December 2020

12. Zhang LF, Li YH, Xie SH, Ling W, Chen SH, Liu Q, Huang QH, Cao SM. Incidence trend of nasopharyngeal carcinoma from 1987 to 2011 in Sihui County, Guangdong Province, South China: an age-period-cohort analysis. Chin J Cancer. 2015;34:15.

13. Tang LL, Chen WQ, Xue WQ, He YQ, Zheng RS, Zeng YX, Jia WH. Global trends in incidence and mortality of nasopharyngeal carcinoma. Cancer Lett. 2016;374:22-30.

14. Li K, Lin GZ, Shen JC, Zhou Q. Time trends of nasopharyngeal carcinoma in urban Guangzhou over a 12-year period (2000-2011): declines in both incidence and mortality. Asian Pac J Cancer Prev. 2014;15:9899-903.

15. Hong Kong Cancer Registry. Nasopharyngeal Cancer in 2018. Hong Kong Hospital Authority. 2020. Available at: https://www3.ha.org.hk/cancereg/ allages.asp. Accessed 24 Dec 2020.
16. Chang ET, Adami H-O. The enigmatic epidemiology of nasopharyngeal carcinoma. Cancer Epidemiol Biomark Prev. 2006;15:1765-77.

17. Jia WH, Qin HD. Non-viral environmental risk factors for nasopharyngeal carcinoma: a systematic review. Semin Cancer Biol. 2012;22:117-26.

18. Yu MC, Huang TB, Henderson BE. Diet and nasopharyngeal carcinoma: a case-control study in Guangzhou, China. Int J Cancer. 1989;43:1077-82.

19. Zheng $Y$, Tuppin $P$, Hubert A, Jeannel D, Pan Y, Zeng Y, De Thé G. Environmental and dietary risk factors for nasopharyngeal carcinoma: a casecontrol study in Zangwu County, Guangxi, China. Br J Cancer. 1994;69:508-14.

20. Gallicchio L, Matanoski G, Tao X, Chen L, Lam TK, Boyd K, Robinson KA, Balick L, Mickelson S, Caulfield LE. Adulthood consumption of preserved and nonpreserved vegetables and the risk of nasopharyngeal carcinoma: a systematic review. Int J Cancer. 2006;119:1125-35.

21. Jia WH, Luo XY, Feng BJ, Ruan HL, Bei JX, Liu WS, Qin HD, Feng QS, Chen LZ, Yao SY. Traditional Cantonese diet and nasopharyngeal carcinoma risk: a largescale case-control study in Guangdong, China. BMC Cancer. 2010;10:1-7.

22. Liu YT, Dai JJ, Xu CH, Lu YK, Fan YY, Zhang XL, Zhang CX, Chen YM. Greater intake of fruit and vegetables is associated with lower risk of nasopharyngeal carcinoma in Chinese adults: a case-control study. Cancer Causes Control. 2012;23:589-99.

23. Polesel J, Serraino D, Negri E, Barzan L, Vaccher E, Montella M, Zucchetto A, Garavello W, Franceschi S, La Vecchia C. Consumption of fruit, vegetables, and other food groups and the risk of nasopharyngeal carcinoma. Cancer Causes Control. 2013;24:1157-65.

24. Feng XX, Wang MX, Li M, Tang X, Jiang H, Wang R, Ma L, Yin Y, Wu CR. Citrus fruit intake and the risk of nasopharyngeal carcinoma. Asia Pac J Clin Nutr. 2019;28:783.

25. Jin J, Ouyang Z, Wang Z. Association of fruit and vegetables with the risk of nasopharyngeal cancer: evidence from a meta-analysis. Sci Rep. 2014;4:5229.

26. Bidoli E, Pelucchi C, Polesel J, Negri E, Barzan L, Franchin G, Franceschi S, Serraino D, Paoli PD, Vecchia CL. Fiber intake and risk of nasopharyngeal carcinoma: a case-control study. Nutrition Cancer. 2013;65:1157-63.

27. Kasum CM, Jacobs DR Jr, Nicodemus K, Folsom AR. Dietary risk factors for upper aerodigestive tract cancers. Int J Cancer. 2002;99:267-72.

28. Lee AW, Ng W, Chan Y, Sze H, Chan C, Lam T. The battle against nasopharyngeal cancer. Radiother Oncol. 2012.

29. Mai ZM, Lin JH, Chiang SC, Ngan RKC, Kwong DLW, Ng WT, Ng AWY, Yuen KT, Ip KM, Chan YH, Lee AWM, Ho SY, Lung ML, Lam TH. Test-retest reliability of a computer-assisted self-administered questionnaire on early life exposure in a nasopharyngeal carcinoma case-control study. Sci Rep. 2018;8:1-7.

30. Mai ZM, Lin JH, Ngan RKC, Kwong DLW, Ng WT, Ng AWY, Yuen KT, Ip DKM, Chan YH, Lee AWM, Ho SY, Lung ML, Lam TH. Milk consumption across life periods in relation to lower risk of nasopharyngeal carcinoma: a multicentre case-control study. Front Oncol. 2019;9:253.

31. Mai ZM, Lin JH, Ngan RKC, Kwong DLW, Ng WT, Ng AWY, Ip KM, Chan YH, Lee AWM, Ho SY, Lung ML, Lam TH. Solar ultraviolet radiation and vitamin $D$ deficiency on Epstein-Barr virus reactivation: observational and genetic evidence from a nasopharyngeal carcinoma endemic population. Open Forum Infect Dis. 2020.

32. Tse L, Yu IT, Mang OW, Wong S. Incidence rate trends of histological subtypes of nasopharyngeal carcinoma in Hong Kong. Br J Cancer. 2006;95:1269-73.

33. Ma Y, Hébert JR, Li W, Bertone-Johnson ER, Olendzki B, Pagoto SL, Tinker L, Rosal MC, Ockene IS, Ockene JK. Association between dietary fiber and markers of systemic inflammation in the Women's Health Initiative observational study. Nutrition. 2008;24:941-9.

34. Krishnamurthy VMR, Wei G, Baird BC, Murtaugh M, Chonchol MB, Raphael $\mathrm{KL}$, Greene T, Beddhu S. High dietary fiber intake is associated with decreased inflammation and all-cause mortality in patients with chronic kidney disease. Kidney Int. 2012;81:300-6.

35. Bosetti C, Pelucchi C, La Vecchia C. Diet and cancer in Mediterranean countries: carbohydrates and fats. Public Health Nutr. 2009;12:1595-600.

36. Willett W. Nutritional epidemiology. Oxford: Oxford university press; 2012. p.7-12.

37. Berkson J. Limitations of the application of fourfold table analysis to hospital data. Int J Epidemiol. 2014:43:511-5.

38. Report of Health Behaviour Survey 2018/19. Hong Kong: noncommunicable disease branch, Centre for health protection, Department of Health; 2020.

\section{Publisher's Note}

Springer Nature remains neutral with regard to jurisdictional claims in published maps and institutional affiliations. 